\title{
STILL SPECIAL AFTER ALL THESE YEARS
}

TO ANSWER THE QUESTION, one needs to consider whether special collections are any more special today than they have been in the past. The question has particularly intrigued me since I was asked to present a paper in November 1976 as part of the University of Texas at Austin Graduate School of Library Science Colloquium Series, to wit_- "What's So Special about Special Collections?"

My perspective was that of a university administrator with line responsibility for one of the great Latin American collections in the world, the most comprehensive collection of Texas-related materials in existence, very young area collections of Asian and Middle East materials, and a two-year-old Mexican American library program. Moreover, I had recently been made chief collection development officer of the university library with responsibility for helping to organize and process the vast collection of rare and special materials that was forming the Harry Ransom Humanities Research Center. These responsibilities had been whetted by personal scholarly and bibliographic pursuits among those collections.

Returning to that paper a quarter of a century later, there continues to be a great deal of resonance. Special collections can vary from subject content to language and area of the world, to format, to level of rarity, to sheer expensiveness, and to the special research value that comprehensiveness of associated materials brings.

Special collections still share in the distinctiveness of the higher level of costs 
they entail because of their frequent expensiveness and acquisition difficulty and because of the need for people with special skills to select, acquire, process, and service them. Additional special expenses include housing, preservation and conservation, and security. These issues are as true today as they were almost twenty-five years ago, just as there will always be a need for collection development policies and aggressive acquisition programs for them, for publicizing and promoting the wide use of those materials that pride of ownership might otherwise discourage.

Exhibitions, special catalogs, and the routine publication of information about the holdings of a special collection were encouraged in that 1976 paper. "Materials must be used, not sealed from use" is as applicable today as it was then. A careful balance between service and preservation continues to be a special concern for special collections.

That earlier paper suggested that "It is increasingly important that institutions share their resources with others" and acknowledged that "The use of machine-based cataloging and indexing systems is going to be an increasing element in accessing special materials." The dimensions of the technological advances that would someday apply to special collections, whether they were used to create digitally encoding finding aids to make holdings more widely known or to digitize materials themselves as a means of sharing them, could not have been readily imagined.

I suggested the usefulness of making special collections more easily available to undergraduate students "by making videotapes ... which could be shown on the closed circuit television monitors in the Undergraduate Library." Digital exhibitions of the treasures held by our libraries have certainly leapt far beyond that notion and our new means of delivering music, video, and other media via the Internet probably will seem primitive in the near future.

Perhaps more than the building of any collection, the development of special collections still represents a singular investment in "anticipation of use." This may suggest investments in objects representative of intellectual, artistic, 
and emotive values that may outweigh their more immediate benefit to the processes of research, learning, and even the preservation of culture.

Extra effort will always be needed to persuade funding authorities that the building of special collections is just as important as the acquisition of current publications, the infrequent use of much of which we generally remain too embarrassed to admit. It is clear that unless special collections are continually enriched, they will become museums bereft of the life that encourages learning and fresh research.

One special concern about such collections pertains today just as it did in the past. And that is the need to identify the role a special collection holds within the institution. How does it relate to the institution's mission and that of its general library collections?

It was cautioned in 1976 that "parochialism, provincialism, elitism are easy traps" for the staff of special collections, with the danger of being "left behind" by the professional progress of staff engaged in broader library activities. Hindsight suggests that the compartmentalization of staff can be just as serious from the other point of view. Staff involved in traditional collections and services should be aware of and understand what their colleagues are about in special collections, branch libraries, and even different functional divisions or departments, just as every other group should be.

Similarities are clear, and changes are apparent between these scenes separated by a quarter century. Financial constraints have somewhat slowed the purchase of rare book collections for academic libraries over that period. But time continues to construct rarities as materials sit in the stacks-or in databases. The growth of area studies collections probably is still not at the anticipated level, and new formats and interests now command attention.

A number of funding opportunities and special projects have led to much greater bibliographic control of library holdings in general, but new digital applications, standards, and the language of the Web will soon enable even 
broader and deeper access than is now the rule. Copyright and intellectual property issues have achieved a level of concern that far transcends that of just a few years ago.

The national waves that have swept across libraries over the past twenty-five years - collection building, bibliographic control, preservation and conservation, resource sharing - are being joined by the sweep of digitization. The ongoing unification of these elements of information management will continue to make our libraries more accessible, less constrained by time and distance.

Special collections will be shared more readily via digital delivery, on-site surrogates, and combinations of media yet to be created. The special expertise of library staff will be shared more broadly, probably online. Competition among libraries, uncurbed by rampant cooperation, will continue as keenly as it always has. 